\title{
Can angiographic vasospasm be used as a surrogate marker in evaluating therapeutic interventions for cerebral vasospasm?
}

\author{
Colum P. Nolan, M.R.C.S.I., And R. Loch Macdonald, M.D., Ph.D. \\ Section of Neurosurgery, Department of Surgery, University of Chicago Medical Center \\ and Pritzker School of Medicine, Chicago, Illinois
}

\begin{abstract}
$\checkmark$ The authors tested the null hypothesis that published literature with a high level of evidence does not support the assertion that subarachnoid hemorrhage (SAH) causes cerebral vasospasm, which in turn causes cerebral infarction and poor outcome after aneurysmal SAH. The medical literature on SAH was searched in MEDLINE. The author's personal files of all published literature on SAH were reviewed. References cited in Cochrane reviews as well as the published papers that were reviewed were also retrieved.

There is no question that SAH causes what the authors have chosen to call "angiographic vasospasm." However, the incidence and severity of vasospasm in recent series of patients is not well defined. There is reasonable evidence that vasospasm causes infarction, but again, accurate data on how severe and how diffuse vasospasm has to be to cause infarction and how often vasospasm is the primary cause of infarction are not available. There are good data on the incidence of cerebral infarction after SAH, and these data indicate that it is highly associated with poor outcome. The link between angiographic vasospasm and poor outcome is particularly poorly described in terms of what would be considered data of a high level of evidence.

The question as to whether there is a clear pathway from SAH to vasospasm to cerebral infarction to poor outcome seems so obvious to neurosurgeons as to make it one not worth asking. Nevertheless, the obvious is not always true or accurate, so it is important to note that published literature only weakly supports the causative association of vasospasm with infarction and poor outcome after SAH. It behooves neurosurgeons to document this seemingly straightforward pathway with high-quality evidence acceptable to the proponents of evidence-based medicine.
\end{abstract}

\section{KEY WORDS • cerebral infarction • cerebral ischemia • cerebral vasospasm • intracranial aneurysm • subarachnoid hemorrhage}

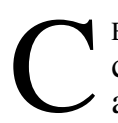
EREBRAL vasospasm is frequently cited as a leading cause of instances of morbidity and mortality after aneurysmal SAH ${ }^{30}$ Its first description, which was based on angiographic findings, is attributed to Ecker and Riemenschneider in 1951. ${ }^{11}$ Although there was some skepticism expressed about the importance of the phenomenon early on, ${ }^{36}$ it has come to be accepted as a major contributor to poor outcome after SAH. ${ }^{34}$ The presumed pathway leading to poor outcome is as follows: SAH causes cerebral vasospasm, which causes cerebral infarction, and cerebral infarction contributes to poor outcome (Fig. 1).

The rigor with which information on clinical medicine is assessed is increasing. Students, regulatory agencies, and increasingly, patients and representatives in industry will not rely on evidence based on expert opinion and case series to decide the best diagnostic and treatment methods. Indeed, these are now regarded as the least powerful forms of information on which to base medical decision making. ${ }^{19}$ Only in the legal profession does such informa-

Abbreviations used in this paper: $\mathrm{CI}=$ confidence interval; $\mathrm{CT}=$ computed tomography; GOS = Glasgow Outcome Scale; $\mathrm{mRS}=$ modified Rankin Scale; RR = relative risk; $\mathrm{SAH}=$ subarachnoid hemorrhage. tion still trump vigorous science. When, for example, one tells officials at the Food and Drug Administration or a person in a drug company who is deciding whether to pursue a treatment for cerebral vasospasm that this condition causes cerebral infarction and poor outcome, so that preventing vasospasm would be beneficial, they will ask to see the data supporting this contention. They also want quantitative data on every aspect of this pathway. Several such encounters led us to search the world literature to find the evidence. The first purpose of this manuscript is therefore to determine what evidence exists to support the pathway from SAH to vasospasm to cerebral infarction to poor outcome.

There are additional reasons for doing this. If such a path were strongly supported by data of a high level of evidence, then this would be a first step in developing the use of angiographic vasospasm and possibly cerebral infarction as surrogate markers for outcome in future clinical trials conducted to evaluate interventions for delayed cerebral vasospasm. Other criteria for surrogate end points are required, for instance, that they make sense pathophysiologically and that they respond to treatment in parallel with a patient-based, long-term outcome measure, but the first step is to establish the relationship outlined here. 


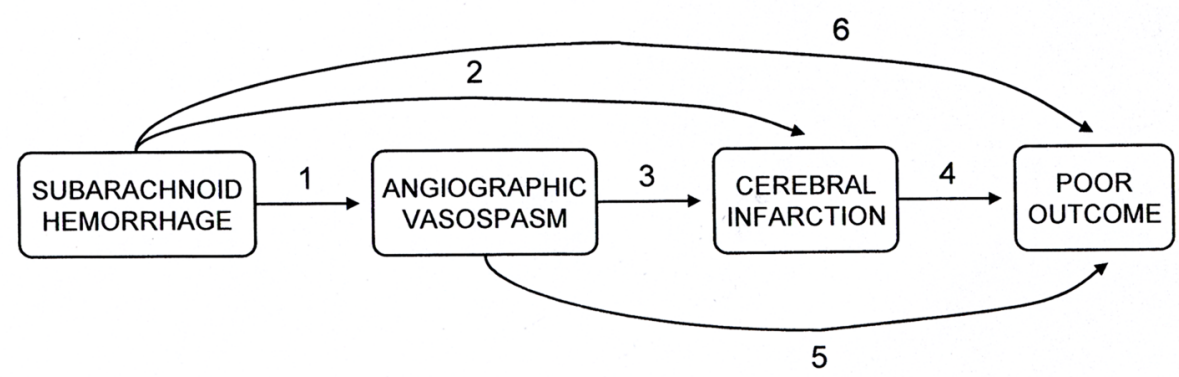

FIG. 1. Flow chart of the pathway examined in this study. The numbers match section subheadings in the paper (except for 6 , which is the only pathway not open to question and therefore is not discussed in depth).

\section{Literature Review}

\section{Definitions of Terminology}

The use of the term "cerebral vasospasm" needs further definition. It can be used to describe the reduction in diameter of the large intradural cerebral arteries 3 to 14 days after SAH as seen on angiography, and this will henceforth be called "angiographic vasospasm." The term "cerebral vasospasm" can also be used to describe neurological worsening associated with this scenario in the absence of other causes, and is more correctly called "clinical" or "symptomatic" vasospasm. Use of the terms clinical or symptomatic vasospasm does not necessarily imply documented angiographic vasospasm. Furthermore, not all patients with angiographic vasospasm have symptoms attributable to it, and vice versa. ${ }^{7,45,52}$ The term "symptomatic vasospasm" is more subjective, because it depends on how exhaustive the efforts are to exclude other causes of neurological worsening. Furthermore, it is complicated because there may be contributing factors, and because patients with poor-grade SAH are more difficult to assess, particularly if they are sedated.

The exact meaning of angiographic vasospasm also varies, because one has to distinguish early from delayed vasospasm. Early vasospasm is typically defined as angiographic vasospasm occurring fewer than 48 hours postSAH. Although it has been shown to be associated with delayed neurological worsening, infarction, and poor outcome, early vasospasm was not found to be related to delayed vasospasm, and thus we will not focus on it here. ${ }^{3}$ Small arteries that cannot be easily observed angiographically were also suggested to contribute to neurological deterioration and morbidity after SAH. ${ }^{39,69}$ The existence and importance of this problem in humans is unknown. Further reference to vasospasm in this article can be assumed to refer to delayed large-artery vasospasm.

Terms such as "delayed cerebral ischemia," "symptomatic vasospasm," and "delayed ischemic neurological deficit" are often used interchangeably in the literature. The definition of these terms is not always the same across studies. Delayed cerebral ischemia (in relation to vasospasm) is a term that can be used to describe the symptoms associated with vasospasm, whether they are transient or not. Therefore, this is primarily a clinical diagnosis, because it does not require angiographic evidence of vasospasm. Because angiography remains the gold standard for diagnosis of vasospasm, a diagnosis of delayed cere- bral ischemia will include some patients in whom deterioration occurs from something other than angiographic vasospasm. There are numerous causes of delayed deterioration. Neurological deterioration is a manifestation of neuronal dysfunction, and some of its causes are not due to ischemia (seizures, hydrocephalus, and perhaps edema and brain shift). Even deterioration due to ischemia has been attributed to causes other than angiographic vasospasm; these include microvascular vasospasm, thromboembolism, and delayed neuronal apoptosis triggered by global ischemia occurring at the time of SAH. ${ }^{38,39,49,52}$ Here we use the term delayed cerebral ischemia to mean ischemia from angiographic vasospasm.

Cerebral infarction due to vasospasm is a radiological diagnosis and results from persistent delayed cerebral ischemia due to angiographic vasospasm. Exactly how severe and extensive angiographic vasospasm has to be to cause infarction is difficult to ascertain. Although those of us with extensive clinical experience in the field have an impression that, with current treatment, angiographic vasospasm must narrow the arteries by more than two thirds and be fairly extensive to cause infarction, quantitative data in the literature are scarce. ${ }^{41}$ When examining the incidence of infarction due to vasospasm, it is important to exclude other causes of infarction, including the following: encephalomalacia from intracerebral hematoma; complications of angiography or endovascular treatment (such as arterial occlusions or thromboembolism); complications of surgery (such as retraction injury); temporary clip placement or arterial occlusions; or indeed any other cause of brain ischemia.

Finally, measures such as the GOS score, mRS score, and Karnofsky Performance Scale score are often used to assess clinical outcome in patients after SAH. Their use is sometimes criticized because of the lack of ability these measures provide to discriminate between normal, fully recovered patients and those with neurological deficits (ceiling effect), which results in falsely categorizing patients as having a good recovery. Patients with cognitive impairment constituted more than $90 \%$ of survivors in one series, and in many, cerebral infarction was demonstrated on magnetic resonance imaging. ${ }^{12}$ Also, the five categories in the GOS are often collapsed into a dichotomous outcome, which decreases discriminative power.

\section{Search Methods}

A MEDLINE search was conducted using "subarach- 
noid hemorrhage" as the key word. Articles were retrieved that contained information relevant to the pathway outlined here. The senior author's files, which contain most of the world literature, including reports published prior to 1966, were reviewed. ${ }^{61} \mathrm{~A}$ textbook on cerebral vasospasm was reviewed. ${ }^{34}$ The literature was summarized and is presented later. This was not a rigorous, systematic review. The findings of such a review would probably be very disappointing.

\section{Results and Discussion}

There are six cause and effect combinations in the pathway (Fig. 1). Perhaps the only one not open to question by skeptics is that SAH causes a poor outcome, so this is not reviewed here.

\section{Does SAH Cause Vasospasm?}

The belief that SAH causes angiographic vasospasm is straightforward and supported by high-quality evidence. Animal models show that vasospasm is caused by SAH. ${ }^{13,27,35}$ We know that the blood from the hemorrhage causes vasospasm, because removing it acutely prevents spasm, and this condition only occurs in the arteries that are encased in blood. ${ }^{15}$ There is very limited evidence for a dose-response effect, in that more blood causes more severe and more prolonged vasospasm, and the longer the $\mathrm{SAH}$ is present, the more sustained and severe vasospasm is. ${ }^{70}$ All of these pieces of evidence have reasonable correlates from human studies. Vasospasm in humans occurs after any condition that deposits blood from SAH in the basal cisterns at an adequate dose and for a long enough time. ${ }^{6,56}$ There are independent correlations among the location, volume, duration of presence, and density (another measure of clot dose) of the hematoma and angiographic vasospasm. . $6,17,46,56$ Furthermore, removing the clot in humans prevents vasospasm. ${ }^{14,62}$ Even though these data are not perfect, because the information has one or more flaws, including retrospective assessment, lack of blinding, small patient numbers, no statistical analysis, and no qualitative end points, clinical experience still is important and the basic premise is hard to deny. In summary, there is an overwhelming body of experimental and clinical experience demonstrating this link.

Another way to assess the relationship is to examine predictors of vasospasm, but there are few such studies. The strongest predictor of delayed cerebral ischemia is clot thickness on admission CT scans. ${ }^{7,33}$ Ischemia in these patients, however, is not always due to vasospasm, and not all patients in this study and other series underwent angiography, which remains the gold standard for detecting angiographic vasospasm. ${ }^{15,23}$ Thus, it is obvious that SAH causes delayed cerebral ischemia, but the contribution of angiographic vasospasm to this condition is not well defined quantitatively.

There are at least two other points to discuss here. First, treatment with nimodipine and hemodynamic maneuvers may have decreased the risk of delayed cerebral ischemia. Despite widespread opinion to the contrary, nimodipine may reduce angiographic vasospasm $\mathrm{m}^{40,41}$ and cerebral infarction. ${ }^{44,47}$ The increasing use of endovascular treatment of aneurysms and the decreasing use of invasive arteriog- raphy in favor of less invasive alternatives (CT or magnetic resonance angiography) may also alter the incidence and severity of angiographic vasospasm after SAH.

Second, some authors suggest that the Fisher scale cannot be used to predict development of vasospasm. ${ }^{54}$ It is not surprising that this could be so, because the measurements and method used by Fisher, et al., ${ }^{16}$ are not easily applied to modern imaging, other factors such as clot clearance are important, small sample sizes can give erroneous results, and vasospasm is usually not angiographically detectable, but the inaccurate surrogate delayed cerebral ischemia has been frequently used as an end point in recent papers.

\section{Does SAH Cause Cerebral Infarction?}

This is necessarily true if the pathway is correct. In 1949, Robertson noted cerebral infarcts in patients who died after aneurysmal SAH. ${ }^{48}$ These lesions were remote from the ruptured aneurysm, and he postulated vascular spasm as the cause. In several subsequent pathological studies it was documented that patients dying of SAH often had infarcts, usually in the territory of the artery containing the aneurysm that had ruptured..$^{8-10,50}$ The arteries were patent at pathological review and the infarcts were suggested to be due to various causes such as vasospasm, hypotension, and hypoxia. Some of these patients had not undergone interventions such as angiography and surgery, excluding iatrogenic causes of infarction. ${ }^{36}$ However, it is difficult to distinguish vasospasm histologically from vasoconstriction and collapse of arteries occurring agonally or postmortem. Because angiography studies usually had not been obtained immediately before death, there was no proof that the infarcts were due to vasospasm. For small infarcts, microthrombi could be a cause because these are not reliably detected on routine histological examination..$^{55}$ Nevertheless, these papers are very important because most of the patients did not undergo either angiography or treatment of their aneurysms, so these studies provide direct evidence that $\mathrm{SAH}$ causes infarction.

In a prospective study of 176 patients who were admitted within 72 hours of SAH and who did not undergo surgery, delayed cerebral ischemia was diagnosed clinically; angiography or transcranial Doppler ultrasonography was not performed in all cases. ${ }^{24}$ Of these patients, 47 (27\%) had infarction on CT scans, and of 18 who died after delayed cerebral ischemia, all had infarcts. In the next section we review more data showing infarction after SAH and delineate the evidence for this step.

In many studies cerebral blood flow was measured after SAH and during vasospasm..$^{26,34,71}$ These data demonstrate reductions in flow but are not very useful for our purposes because changes in flow do not equate to infarction. The values for thresholds of ischemia and infarction in humans are not even well known. ${ }^{4}$ In any case, this part of the pathway is accurate despite limitations of the data.

\section{Does Vasospasm Cause Cerebral Infarction?}

Even though it seems obvious, support for this hypothesis is based on only very limited retrospective studies in which vasospasm was documented using angiography. Most of this work is compromised by selective use of angiography, which introduces diagnostic uncertainty. The 
severity and extent of vasospasm that is needed to cause infarction and the frequency of infarction due to angiographic vasospasm is not easily discerned from the literature.

Ohta and Ito $^{42}$ retrospectively reviewed 135 patients with ruptured aneurysms. Vasospasm developed in 92 $(68 \%)$ of these patients, as demonstrated on angiographic studies, and infarction occurred in the territory of the vasospastic artery in $29(21 \%)$. The authors concluded that $\mathrm{SAH}$ led to vasospasm and subsequently to infarction. The limitations are that this was a retrospective review performed by physicians who were not blinded to the diagnosis, although the findings have been confirmed in other retrospective reviews. Graham and colleagues ${ }^{18}$ performed postmortem examinations in patients who had died after SAH from a ruptured aneurysm. Of 34 hemispheres with ischemic brain damage (28 arterial territory, six boundary zone), 22 (65\%) were considered to have pathological vasospasm, whereas spasm was only detected in four $(18 \%)$ of the 22 hemispheres with no evidence of ischemic brain damage. Furthermore, $77 \%$ of hemispheres without intracerebral hematoma but with arterial territory infarction had spasm, whereas only $17 \%$ of such hemispheres had spasm but no infarction. These authors also asserted that severe spasm correlated significantly with the presence of infarction, particularly in patients with arterial territory ischemia, although quantification of vasospasm was not performed.

In a prospective study of 265 patients, Ohman, et al., ${ }^{41}$ examined the incidence of angiographic vasospasm and cerebral infarction with respect to nimodipine. This study only included good-grade patients, 223 of whom were available for follow up and underwent CT scanning at a mean of 1.4 years post-SAH. In patients with moderate to severe vasospasm ( $>30 \%$ luminal diameter reduction) on postoperative angiographic studies, $65 \%$ had infarction on follow-up CT scans, which was significantly higher than the number with infarction and no vasospasm (for infarction in patients without vasospasm compared with those in whom vasospasm was found: RR $0.38,95 \%$ CI $0.2-0.74$ ). Infarctions were usually located in the territory of the artery harboring the ruptured aneurysm.

Rabinstein and colleagues ${ }^{45}$ retrospectively reviewed data obtained in 143 patients with aneurysmal SAH to identify risk factors for cerebral infarction. These authors' definition of infarction excluded causes that were unlikely to be due to vasospasm, but the definition of symptomatic vasospasm did not require angiography, so it is diagnostically uncertain whether angiographic vasospasm was present. Symptomatic vasospasm occurred in $49 \%$ of patients and infarcts occurred in $40 \%$. Of patients with infarcts, symptomatic vasospasm was diagnosed in $89 \%$. In a multivariate analysis, these authors found that symptomatic vasospasm and transcranial Doppler ultrasonography or angiographic vasospasm were independent risk factors for infarction.

In a logistic regression performed on data obtained in the 3567 patients entered into four randomized blinded trials of tirilazad, it was found that infarction was highly and independently associated with delayed cerebral ischemia (RL Macdonald, unpublished observations). ${ }^{20,29,31,32}$ These data are compromised because angiography was not performed and the suspected cause of the infarction was not known.
Important data can be derived from clinical trials of protocols that reduced vasospasm and cerebral infarction. ${ }^{41,59,67}$ This is key because these studies simply show a relationship between the two, but do not provide information on cause and effect. Demonstrating a reduction in infarction in association with reduced angiographic vasospasm supports causality and also is an important component of the development of angiographic vasospasm as a surrogate marker. Unfortunately, the studies on which to base this conclusion are not robust, which is fuel for skeptics. In other words, for each drug study yielding positive results, there are as many or more with negative findings. In the randomized blinded trial of nimodipine conducted by Ohman, et al., ${ }^{41}$ nimodipine significantly reduced angiographic vasospasm, delayed cerebral ischemia (which decreased from $28 \%$ in the placebo group to $14 \%$ with nimodipine), and cerebral infarction. There was no effect on outcome, which then requires one of three conclusions. Either the link between angiographic vasospasm, infarction, and outcome is incorrect, or one has to hypothesize that nimodipine also has detrimental side effects or that rescue therapy is equally effective and was used more in the placebo group. Also, in other trials of nimodipine, investigators did not find a difference in angiographic vasospasm. ${ }^{43}$

The cooperative aneurysm studies for nicardipine reveal a similar picture. ${ }^{21,22}$ In these investigations, 906 patients with recent aneurysmal SAH in all neurological grades and a balance of prognostic factors for vasospasm were randomized to receive either nicardipine or placebo. Clinical vasospasm developed in $32 \%$ of patients in the nicardipine group, compared with $46 \%$ in the placebo group $(\mathrm{p}<0.001)$. There were no statistical differences, however, in the rates of infarction or outcome measures. This may be explained by the fact that, although patients in both groups had similar rates of prophylactic hemodynamic therapy, those in the placebo group had higher rates of intentional therapeutic hemodynamic therapy (38\% compared with $25 \%$; $p<0.001$ ). In $23 \%$ of nicardipinetreated patients and in $26 \%$ of those who received placebo, angiography was performed during the expected period of maximal vasospasm (Days 7-11), with 33\% of patients in the nicardipine group experiencing moderate to severe angiographic vasospasm compared with $51 \%$ in the placebo group. This reduction in angiographic vasospasm in the nicardipine group correlates well with the reduction in clinical vasospasm, although this was not borne out when outcome measures and infarction rates are included as discussed earlier. Another consideration is that there may have been a selection bias in choosing the patients who underwent angiography.

A randomized trial in which enoxaparin was compared with placebo in good-grade patients included 117 participants and examined ischemic sequelae after SAH. ${ }^{67} \mathrm{In}-$ traoperative or postoperative angiography was performed in 82 patients $(70 \%)$. There were significant decreases in localized angiographic vasospasm (16\% in the enoxaparin group compared with $48 \%$ in patients receiving placebo), which were associated with a significant decrease in infarction from vasospasm (4\% of enoxaparin-treated patients compared with $28 \%$ of patients receiving placebo). Conversely, another randomized blinded study of enoxaparin showed no statistical difference in angiographic 
vasospasm, delayed cerebral ischemia, infarction, or outcome after aneurysmal SAH. ${ }^{53}$

Finally, although results of the first trial of a nonselective endothelin receptor antagonist were negative, ${ }^{51}$ a Phase IIa blinded trial of the selective endothelin receptor A antagonist clazosentan was more favorable..$^{59}$ Of 32 patients randomized to receive clazosentan or placebo, $40 \%$ in the clazosentan group experienced angiographic vasospasm (> 33\% luminal narrowing) compared with $88 \%$ in the placebo group, and the severity of the vasospasm was also significantly less with clazosentan. New infarctions were present in 31 and $50 \%$ in the clazosentan and placebo groups, respectively ( $15 \%$ compared with $44 \%$ in the on-treatment analysis).

\section{Does Cerebral Infarction Cause Poor Outcome?}

Angiography was not performed in all cases in any of these studies, so there is great difficulty in using them to establish a relationship between angiographic vasospasm and delayed cerebral ischemia, or between angiographic vasospasm and poor outcome. Some reports have multiple limitations, including univariate analysis only, limited documentation of how infarction was diagnosed, and selective application of diagnostic tests. ${ }^{57}$ Because of this one cannot discern the independent effects of infarction on outcome, and therefore they are not considered further. Also, none of these studies includes a substantial number of patients who underwent endovascular treatment, or no statement is made about treatment methods. ${ }^{60}$

Juvela ${ }^{28}$ examined 242 of 291 patients who survived the initial hemorrhage and were alive for at least 4 days. Of the 242 patients, delayed cerebral ischemia developed in $90(37 \%)$, and $54(22 \%)$ either had fixed deficits or died. Of 195 patients who were available for CT scanning at 1 year, $44 \%$ had infarcts that were considered probably secondary to vasospasm. Delayed cerebral ischemia was significantly associated with infarction on follow-up CT scans, and patients in whom a fixed deficit arose from delayed cerebral ischemia associated with infarction had a significantly increased likelihood of unfavorable outcome.

Claassen, et al., ${ }^{7}$ defined delayed cerebral ischemia as unexplained clinical deterioration and/or a new infarct present on CT scans that was not present shortly after aneurysm treatment. Angiographic confirmation was not required. The incidence of delayed cerebral ischemia in 276 patients with SAH was $20 \%$ (54 patients). Of the 54 patients, cerebral infarction was present in 34 (63\%). The mortality rate at 3 months was not associated with delayed cerebral ischemia, although a worse 3-month outcome on the mRS was. Therefore, there was not a robust association between delayed cerebral ischemia and outcome, but in this study the investigators were not directly examining cerebral infarction. Similar findings were reported in a retrospective review by Shimoda, et al., ${ }^{52}$ who found that cerebral infarction was associated with poor outcome but that the relationship of delayed cerebral ischemia to outcome was less obvious. No statistical analysis of these data was performed.

Woertgen and colleagues ${ }^{66}$ retrospectively defined delayed cerebral ischemia as a new infarct on CT scans that was not present on admission or within 1 day of aneurysm surgery. Patients who underwent endovascular treatment were excluded. In this study, 83 (28\%) of 292 patients had an infarct that probably resulted from vasospasm, although angiography was not performed, so we cannot use these data to link angiographic vasospasm to infarction or outcome. Delayed cerebral ischemia was significantly correlated to outcome, in that only $9 \%$ of patients with a good outcome had delayed cerebral ischemia, whereas $62 \%$ of patients with an unfavorable outcome had this condition. An important limitation, however, is that other variables that may affect outcome were not included in the analysis. A multivariate analysis using logistic regression, proportional odds models, or other techniques must be done.

Retrospective analysis showed that 57 of 143 patients with aneurysmal SAH had evidence of infarction on CT scans that could not be attributed to complications of surgery or angiography. ${ }^{45}$ Most of the infarcts were probably due to vasospasm, but angiographic studies were not always obtained to document this. Cerebral infarction was significantly predictive of poor outcome, with a mean $\mathrm{mRS}$ score of 1 in patients with no infarct compared with a score of 3 in patients with an infarct.

The randomized trial comparing enoxaparin with placebo in 117 good-grade patients with SAH was discussed earlier. ${ }^{67}$ The relationship of infarction to outcome was not examined, but the data show that enoxaparin treatment was associated with reduced localized angiographic vasospasm and cerebral infarction, and with improved outcome at 2 months on the GOS score. Concomitant improvement in outcome and a reduction in infarction support a causative relationship and the potential use of infarction as a surrogate outcome measure. One limitation, also mentioned earlier, is the lack of effect observed in another similar study of enoxaparin..$^{53}$

There are other examples of covariance of infarction and outcome. A Cochrane review of calcium antagonists for aneurysmal SAH included 12 unconfounded randomized trials. ${ }^{47}$ Nimodipine was used in eight trials and nicardipine in two, but in the other trials a different class of drug (AT877, which is a Rho kinase inhibitor, and magnesium sulfate, which has multiple actions) was used. This does not alter the association shown, which was that a reduction in delayed cerebral ischemia and infarction was associated with improved outcome. Delayed cerebral ischemia was reduced from $452(40 \%)$ of 1124 patients in the control groups to 288 (27\%) of 1063 patients (RR $0.67,95 \%$ CI $0.60-0.76)$ in the treatment groups. Infarction observed on CT scans, which would not necessarily be due to vasospasm, occurred in $303(37 \%)$ of 821 of the treated patients and in $47 \%$ of the control patients (RR $0.80,95 \%$ CI $0.71-0.89)$. Of the eight trials in which functional outcome measures were used, there was a risk of poor outcome after treatment (RR 0.82 , 95\% CI 0.72 0.93 ) and an absolute risk reduction of $5 \%$. Data in the largest nimodipine trial showed similar results. ${ }^{44}$ Among the 554 patients with 3 months of follow-up review, the incidence of cerebral infarction from all causes was 61 $(22 \%)$ of 278 in the treatment group compared with 92 (33\%) of 276 in the control group on an intention-to-treat basis, a significant difference. Poor outcomes were 20 and $33 \%$ for the treatment and control groups, respectively.

A European study published in 2005 reported on 283 
patients who were randomized to receive magnesium sulfate or placebo. ${ }^{60}$ The results showed a link between alteration of delayed cerebral ischemia (defined as a new hypodense lesion on CT scans that correlates with clinical symptoms of vasospasm) and alteration of outcome. The risk of delayed cerebral ischemia was reduced by $34 \%$ in the magnesium group according to the on-treatment analysis, and the risk of poor outcome was reduced by $23 \%$ in the intention-to-treat analysis.

\section{Does Angiographic Vasospasm Cause Poor Outcome?}

It would be optimal to have data showing that this is true, because it must be if the pathway is correct. This evidence, however, is disappointingly elusive. Arguably one of the best studies remains a retrospective one that included 274 patients with aneurysms, 251 of which were ruptured. ${ }^{63}$ Multiple regression analysis showed that preoperative angiographic vasospasm was the second most important factor (after clinical grade) associated with 2month survival among 135 patients treated surgically. All patients with no postoperative angiographic vasospasm were alive at 2 months. In $39 \%$ of patients preoperative angiograms were obtained at least 4 days postictus, so we can assume that preoperative vasospasm in this context would have included a large number with delayed cerebral vasospasm.

A prospective, multivariate analysis of a cooperative study used death as the dependent variable. ${ }^{58}$ Independent factors associated with death were, in order of importance, neurological status, diastolic blood pressure, interval to treatment, a qualitative assessment of angiographic vasospasm at no set time after SAH, and medical condition. A retrospective multivariate analysis of 265 patients with SAH yielded similar findings, with survival affected by admission neurological grade, age, blood pressure, longer time from SAH to surgery, and aneurysm side. ${ }^{2}$ Each of these three studies is limited by the fact that angiography was performed at various times after $\mathrm{SAH}$, so the absence of vasospasm could be due to the failure to perform angiography at the correct time after SAH., ${ }^{2,58,63}$

The enoxaparin trial has been discussed earlier in this paper, but the findings have a bearing on this relationship because they show covariance in angiographic vasospasm and outcome. ${ }^{67}$ Not all patients underwent angiography (82 [70\%] of 117), which introduces bias, but in the ones who did there was a significant decrease in localized angiographic vasospasm and improvement in outcome in the enoxaparin-treated group.

Numerous other studies show that delayed cerebral ischemia is associated with poor outcome, but angiographic vasospasm was not assessed in these studies or the data are too vague to show the relationship accurately and statistically. ${ }^{6,25,37}$ The nicardipine studies confuse the relationship because they demonstrate a dissociation between angiographic vasospasm, cerebral infarction, and outcome. $^{21,22}$ In the Cooperative Aneurysm Study, 906 patients with aneurysmal SAH were randomly allocated to receive treatment with nicardipine or placebo. Outcome, incidence, and size of cerebral infarcts at 3-month follow up were identical between groups, yet angiographic vasospasm was less frequent in the treated patients. Only a subset of patients underwent angiography and not all had follow-up CT scans, which could introduce bias, but one has to invoke other mechanisms to explain the results. It is possible that hemodynamic therapy, which was used more often in patients receiving placebo, was effective enough to offset the benefit of nicardipine. It is unlikely that nicardipine was harmful, because delayed cerebral ischemia was less common in the nicardipine-treated group. If this agent had adverse effects such as hypotension, then there should have been at least as much if not more delayed cerebral ischemia in the nicardipine group.

These data are further limited by the absence of patients treated using endovascular procedures and of those undergoing current treatment methods. This limitation makes it difficult to derive any accurate, quantitative information on what degree and extent of angiographic vasospasm leads to infarction, what the frequency and extent of infarction is, and how exactly this relates to outcome.

\section{Conclusions}

Cerebral vasospasm is probably a leading cause of morbidity and death after aneurysmal SAH. Overall, there are demonstrable correlations between SAH, vasospasm, delayed cerebral ischemia/infarction, and outcome. The strongest links are between SAH and angiographic vasospasm, SAH and cerebral infarction, and cerebral infarction and outcome. The data linking angiographic vasospasm to cerebral infarction and to outcome are somewhat weak. Not enough evidence is available to prove that angiographic vasospasm in itself could be used as a surrogate marker to monitor disease progression and efficacy of intervention.

Based on the results of clinical trials, conventional catheter angiography is used infrequently to diagnose vasospasm. Conventional angiography remains the gold standard, so failing to perform it makes it difficult to use vasospasm as an end point in a clinical trial. Conventional angiography is an invasive modality, and the use of less invasive techniques of proven specificity and sensitivity would be welcome. Promising reports include multidetector-row CT angiography ${ }^{65,68}$ and the combination of CT angiography with perfusion CT scanning, ${ }^{64}$ and such modalities may become targets as surrogate markers themselves in the future.

\section{Disclosure}

Dr. Macdonald received grant support from Boston Scientific and consultant fees from Actelion Pharmaceuticals.

\section{References}

1. Adams HPJ, Kassell NF, Torner JC, Haley EC Jr: Predicting cerebral ischemia after aneurysmal subarachnoid hemorrhage: influences of clinical condition, CT results, and antifibrinolytic therapy. A report of the Cooperative Aneurysm Study. Neurology 37:1586-1591, 1987

2. Artiola I, Fortuny L, Prieto-Valiente L: Long-term prognosis in surgically treated intracranial aneurysms. Part 1: mortality. J Neurosurg 54:26-34, 1981

3. Baldwin ME, Macdonald RL, Huo D, Novakovic RL, Goldenberg FD, Frank JI, et al: Early vasospasm on admission angiog- 
raphy in patients with aneurysmal subarachnoid hemorrhage is a predictor for in-hospital complications and poor outcome. Stroke 35:2506-2511, 2004

4. Bandera E, Botteri M, Minelli C, Sutton A, Abrams KR, Latronico N, et al: Cerebral blood flow threshold of ischemic penumbra and infarct core in acute ischemic stroke: a systematic review. Stroke 37:1334-1339, 2006

5. Brouwers PJ, Dippel DW, Vermeulen M, Lindsay KW, Hasan D, van Gijn J, et al: Amount of blood on computed tomography as an independent predictor after aneurysm rupture. Stroke 24: 809-814, 1993

6. Charpentier C, Audibert G, Guillemin F, Civit T, Ducrocq X, Bracard S, et al: Multivariate analysis of predictors of cerebral vasospasm occurrence after aneurysmal subarachnoid hemorrhage. Stroke 30:1402-1408, 1999

7. Claassen J, Bernardini GL, Kreiter K, Bates J, Du YE, Copeland D, et al: Effect of cisternal and ventricular blood on risk of delayed cerebral ischemia after subarachnoid hemorrhage: the Fisher scale revisited. Stroke 32:2012-2020, 2001

8. Crompton MR: Cerebral infarction following the rupture of cerebral berry aneurysms. Brain 87:263-285, 1964

9. Crompton MR: The pathogenesis of cerebral infarction following the rupture of cerebral berry aneurysms. Brain 87:491-510, 1964

10. Crompton MR: The pathology of ruptured middle cerebral aneurysms with special reference to differences between the sexes. Lancet 2:421-425, 1962

11. Ecker A, Riemenschneider PA: Arteriographic demonstration of spasm of the intracranial arteries with special reference to saccular arterial aneurysms. J Neurosurg 8:660-667, 1951

12. Egge A, Sjoholm H, Waterloo K, Solberg T, Ingebrigtsen T, Romner B, et al: Serial single-photon emission computed tomographic and transcranial doppler measurements for evaluation of vasospasm after aneurysmal subarachnoid hemorrhage. Neurosurgery 57:237-242, 2005

13. Espinosa F, Weir B, Boisvert D, Overton T, Castor W: Chronic cerebral vasospasm after large subarachnoid hemorrhage in monkeys. J Neurosurg 57:224-232, 1982

14. Findlay JM, Kassell NF, Weir BK, Haley EC Jr, Kongable G, Germanson T, et al: A randomized trial of intraoperative, intracisternal tissue plasminogen activator for the prevention of vasospasm. Neurosurgery 37:168-178, 1995

15. Findlay JM, Weir BK, Steinke D, Tanabe T, Gordon P, Grace M, et al: Effect of intrathecal thrombolytic therapy on subarachnoid clot and chronic vasospasm in a primate model of SAH. J Neurosurg 69:723-735, 1988

16. Fisher CM, Kistler JP, Davis JM: Relation of cerebral vasospasm to subarachnoid hemorrhage visualized by computerized tomographic scanning. Neurosurgery 6:1-9, 1980

17. Friedman JA, Goerss SJ, Meyer FB, Piepgras DG, Pichelmann MA, McIver JI, et al: Volumetric quantification of Fisher Grade 3 aneurysmal subarachnoid hemorrhage: a novel method to predict symptomatic vasospasm on admission computerized tomography scans. J Neurosurg 97:401-407, 2002

18. Graham DI, Macpherson P, Pitts LH: Correlation between angiographic vasospasm, hematoma, and ischemic brain damage following SAH. J Neurosurg 59:223-230, 1983

19. Guyatt GH, Haynes RB, Jaeschke RZ, Cook DJ, Green L, Naylor CD, et al: Users' guides to the medical literature: XXV. Evidence-based medicine: principles for applying the users' guides to patient care. Evidence-Based Medicine Working Group. JAMA 284:1290-1296, 2000

20. Haley EC Jr, Kassell NF, Apperson-Hansen C, Maile MH, Alves WM, et al: A randomized, double-blind, vehicle-controlled trial of tirilazad mesylate in patients with aneurysmal subarachnoid hemorrhage: a cooperative study in North America. J Neurosurg 86:467-474, 1997

21. Haley EC Jr, Kassell NF, Torner JC: A randomized controlled trial of high-dose intravenous nicardipine in aneurysmal sub- arachnoid hemorrhage. A report of the Cooperative Aneurysm Study. J Neurosurg 78:537-547, 1993

22. Haley EC Jr, Kassell NF, Torner JC: A randomized trial of nicardipine in subarachnoid hemorrhage: angiographic and transcranial Doppler ultrasound results. A report of the Cooperative Aneurysm Study. J Neurosurg 78:548-553, 1993

23. Hijdra A, van Gijn J, Nagelkerke NJ, Vermeulen M, van Crevel $\mathrm{H}$ : Prediction of delayed cerebral ischemia, rebleeding, and outcome after aneurysmal subarachnoid hemorrhage. Stroke 19: 1250-1256, 1988

24. Hijdra A, van Gijn J, Stefanko S, Van Dongen KJ, Vermeulen $\mathrm{M}$, Van Crevel H, et al: Delayed cerebral ischemia after aneurysmal subarachnoid hemorrhage: clinicoanatomic correlations. Neurology 36:329-333, 1986

25. Hoh BL, Topcuoglu MA, Singhal AB, Pryor JC, Rabinov JD, Rordorf GA, et al: Effect of clipping, craniotomy, or intravascular coiling on cerebral vasospasm and patient outcome after aneurysmal subarachnoid hemorrhage. Neurosurgery 55: 779-789, 2004

26. James IM: Changes in cerebral blood flow and in systemic arterial pressure following spontaneous subarachnoid haemorrhage. Clin Sci 35:11-22, 1968

27. Johshita H, Kassell NF, Sasaki T, Nakagomi T, Ogawa H: Biphasic constriction of rabbit basilar artery following experimental subarachnoid hemorrhage: a morphometric study. Surg Neurol 37:106-114, 1992

28. Juvela S: Aspirin and delayed cerebral ischemia after aneurysmal subarachnoid hemorrhage. J Neurosurg 82:945-952, 1995

29. Kassell NF, Haley EC, Apperson-Hansen C, Alves WM: Randomized, double-blind, vehicle-controlled trial of tirilazad mesylate in patients with aneurysmal subarachnoid hemorrhage: a cooperative study in Europe, Australia, and New Zealand. J Neurosurg 84:221-228, 1996

30. Kassell NF, Torner JC, Haley EC Jr, Jane JA, Adams HP, Kongable GL, et al: The International Cooperative Study on the Timing of Aneurysm Surgery. Part 1: overall management results. J Neurosurg 73:18-36, 1990

31. Lanzino G, Kassell NF: Double-blind, randomized, vehiclecontrolled study of high-dose tirilazad mesylate in women with aneurysmal subarachnoid hemorrhage. Part II. A cooperative study in North America. J Neurosurg 90:1018-1024, 1999

32. Lanzino G, Kassell NF, Dorsch NW, Pasqualin A, Brandt L, Schmiedek P: Double-blind, randomized, vehicle-controlled study of high-dose tirilazad mesylate in women with aneurysmal subarachnoid hemorrhage. Part I. A cooperative study in Europe, Australia, New Zealand, and South Africa. J Neurosurg 90:1011-1017, 1999

33. Macdonald RL, Rosengart A, Huo D, Karrison T: Factors associated with the development of vasospasm after planned surgical treatment of aneurysmal subarachnoid hemorrhage. J Neurosurg 99:644-652, 2003

34. Macdonald RL, Weir B: Cerebral Vasospasm. San Diego: Academic Press, 2001

35. Mayberg MR, Okada T, Bark DH: The significance of morphological changes in cerebral arteries after subarachnoid hemorrhage. J Neurosurg 72:626-633, 1990

36. Millikan $\mathrm{CH}$ : Cerebral vasospasm and ruptured intracranial aneurysm. Arch Neurol 32:433-449, 1975

37. Niskanen MM, Hernesniemi JA, Vapalahti MP, Kari A: Oneyear outcome in early aneurysm surgery: prediction of outcome. Acta Neurochir (Wien) 123:25-32, 1993

38. Ohkuma H, Itoh K, Shibata S, Suzuki S: Morphological changes of intraparenchymal arterioles after experimental subarachnoid hemorrhage in dogs. Neurosurgery 41:230-236, 1997

39. Ohkuma H, Manabe H, Tanaka M, Suzuki S: Impact of cerebral microcirculatory changes on cerebral blood flow during cerebral vasospasm after aneurysmal subarachnoid hemorrhage. Stroke 31:1621-1627, 2000

40. Ohman J, Heiskanen O: Effect of nimodipine on the outcome of 
patients after aneurysmal subarachnoid hemorrhage and surgery. J Neurosurg 69:683-686, 1988

41. Ohman J, Servo A, Heiskanen O: Risk factors for cerebral infarction in good-grade patients after aneurysmal subarachnoid hemorrhage and surgery: a prospective study. J Neurosurg 74: 14-20, 1991

42. Ohta H, Ito Z: Cerebral infarction due to vasospasm, revealed by computed tomography. Neurol Med Chir 21:365-372, 1981

43. Petruk KC, West M, Mohr G, Weir BK, Benoit BG, Gentili F, et al: Nimodipine treatment in poor-grade aneurysm patients. Results of a multicenter double-blind placebo-controlled trial. J Neurosurg 68:505-517, 1988

44. Pickard JD, Murray GD, Illingworth R, Shaw MD, Teasdale GM, Foy PM, et al: Effect of oral nimodipine on cerebral infarction and outcome after subarachnoid haemorrhage: British Aneurysm Nimodipine Trial. BMJ 298:636-642, 1989

45. Rabinstein AA, Friedman JA, Weigand SD, McClelland RL, Fulgham JR, Manno EM, et al: Predictors of cerebral infarction in aneurysmal subarachnoid hemorrhage. Stroke 35: 1862-1866, 2004

46. Reilly C, Amidei C, Tolentino J, Jahromi BS, Macdonald RL: Clot volume and clearance rate as independent predictors of vasospasm after aneurysmal subarachnoid hemorrhage. J Neurosurg 101:255-261, 2004

47. Rinkel GJ, Feigin VL, Algra A, Vermeulen M, van Gijn J: Calcium antagonists for aneurysmal subarachnoid haemorrhage. Cochrane Database Syst Rev:CD000277, 2005

48. Robertson EG: Cerebral lesions due to intracranial aneurysms. Brain 72:150-185, 1949

49. Romano JG, Forteza AM, Concha M, Koch S, Heros RC, Morcos JJ, et al: Detection of microemboli by transcranial Doppler ultrasonography in aneurysmal subarachnoid hemorrhage. Neurosurgery 50:1026-1031, 2002

50. Schneck SA, Kricheff II: Intracranial aneurysm rupture, vasospasm, and infarction. Arch Neurol 11:668-680, 1964

51. Shaw MD, Vermeulen M, Murray GD, Pickard JD, Bell BA, Teasdale GM: Efficacy and safety of the endothelin, receptor antagonist TAK-044 in treating subarachnoid hemorrhage: a report by the Steering Committee on behalf of the UK/Netherlands/Eire TAK-044 Subarachnoid Haemorrhage Study Group. J Neurosurg 93:992-997, 2000

52. Shimoda M, Takeuchi M, Tominaga J, Oda S, Kumasaka A, Tsugane R: Asymptomatic versus symptomatic infarcts from vasospasm in patients with subarachnoid hemorrhage: serial magnetic resonance imaging. Neurosurgery 49:1341-1350, 2001

53. Siironen J, Juvela S, Varis J, Porras M, Poussa K, Ilveskero S, et al: No effect of enoxaparin on outcome of aneurysmal subarachnoid hemorrhage: a randomized, double-blind, placebocontrolled clinical trial. J Neurosurg 99:953-959, 2003

54. Smith ML, Abrahams JM, Chandela S, Smith MJ, Hurst RW, Le Roux PD: Subarachnoid hemorrhage on computed tomography scanning and the development of cerebral vasospasm: the Fisher grade revisited. Surg Neurol 63:229-235, 2005

55. Stein SC, Graham DI, Chen XH, Dunn L, Smith DH: Apo E genotype not associated with intravascular coagulation in traumatic brain injury. Neurosci Lett 387:28-31, 2005

56. Takemae T, Mizukami M, Kin H, et al: [Computed tomography of ruptured intracranial aneurysms in acute stage-relationship between vasospasm and high density on CT scan (author's transl).] No To Shinkei 30:861-866, 1978 (Jpn)

57. Taylor B, Harries P, Bullock R: Factors affecting outcome after surgery for intracranial aneurysm in Glasgow. Br J Neurosurg 5:591-600, 1991

58. Torner JC, Kassell NF, Wallace RB, Adams HP Jr: Preoperative prognostic factors for rebleeding and survival in aneurysm patients receiving antifibrinolytic therapy: report of the cooperative aneurysm study. Neurosurgery 9:506-513, 1981

59. Vajkoczy P, Meyer B, Weidauer S, Raabe A, Thome C, Ringel $\mathrm{F}$, et al: Clazosentan, a novel selective endothelin A receptor antagonist prevents cerebral vasospasm following aneurysmal SAH. J Neurosurg 102:A415, 2005 (Abstract)

60. van den Bergh WM, Algra A, van Kooten F, Dirven CM, van Gijn J, et al: Magnesium sulfate in aneurysmal subarachnoid hemorrhage: a randomized controlled trial. Stroke 36: 1011-1015, 2005

61. Weir B: Aneurysms Affecting the Nervous System. Baltimore: Williams \& Wilkins, 1987

62. Weir B: The effect of clot removal on cerebral vasospasm. Neurosurg Clin N Am 1:377-385, 1990

63. Weir B, Rothberg C, Grace M, Davis F: Relative prognostic significance of vasospasm following subarachnoid hemorrhage. Can J Neurol Sci 2:109-114, 1975

64. Wintermark M, Ko NU, Smith WS, Liu S, Higashida RT, Dillon WP: Vasospasm after subarachnoid hemorrhage: utility of perfusion CT and CT angiography on diagnosis and management. AJNR Am J Neuroradiol 27:26-34, 2006

65. Wintermark M, Uske A, Chalaron M, Regli L, Maeder P, Meuli $\mathrm{R}$, et al: Multislice computerized tomography angiography in the evaluation of intracranial aneurysms: a comparison with intraarterial digital subtraction angiography. J Neurosurg 98: 828-836, 2003

66. Woertgen C, Ullrich OW, Rothoerl RD, Brawanski A: Comparison of the Claassen and Fisher CT classification scale to predict ischemia after aneurysmatic SAH. Zentralbl Neurochir 64:104-108, 2003

67. Wurm G, Tomancok B, Nussbaumer K, Adelwohrer C, Holl K: Reduction of ischemic sequelae following spontaneous subarachnoid hemorrhage: a double-blind, randomized comparison of enoxaparin versus placebo. Clin Neurol Neurosurg 106: 97-103, 2004

68. Yoon DY, Choi CS, Kim KH, Cho BM: Multidetector-row CT angiography of cerebral vasospasm after aneurysmal subarachnoid hemorrhage: comparison of volume-rendered images and digital subtraction angiography. AJNR Am J Neuroradiol 27: 370-377, 2006

69. Yundt KD, Grubb RL Jr, Diringer MN, Powers WJ: Autoregulatory vasodilation of parenchymal vessels is impaired during cerebral vasospasm. J Cereb Blood Flow Metab 18: 419-424, 1998

70. Zabramski JM, Spetzler RF, Bonstelle C: Chronic cerebral vasospasm: effect of volume and timing of hemorrhage in a canine model. Neurosurgery 18:1-6, 1986

71. Zingesser LH, Schechter MM, Dexter J, Katzman R, Scheinberg LC: On the significance of spasm associated with rupture of a cerebral aneurysm. The relationship between spasm as noted angiographically and regional blood flow determinations. Arch Neurol 18:520-528, 1968

Manuscript received June 16, 2006.

Accepted in final form August 4, 2006.

Drs. Nolan and Macdonald are supported by grants from the National Institutes of Health (R01 NS25946) and the American Heart Association.

Address reprint requests to: R. Loch Macdonald, M.D., Section of Neurosurgery, MC3026, University of Chicago Medical Center, 5841 South Maryland Avenue, Chicago, Illinois 60637. email: rlmacdon@uchicago.edu. 